Brit. J. Psychiat. (1976), 129, 286-8

\title{
Correspondence
}

Letters for publication in the Correspondence columns should be addressed to:

The Editor, British Journal of Psychiatry, 17 Belgrave Square, London SWIX 8PG

\section{THE HOMELESS PERSON AND THE PSYCHIATRIC SERVICES}

Dear Sir,

Priest's conclusion in 'The homeless person and the psychiatric services: an Edinburgh survey' (Joumal, February 1976, 128, pp 128-36) that 'subjects presenting to the psychiatric services are a highly selected group quite unrepresentative of homeless single persons in general' seems unremarkable. Isn't it just what we would expect? What would be interesting would be if the two samples were alike, and isn't the same true of the general population? Priest doesn't seem to have tried such comparison, essential though it seems. He says 'it must be remarkable in any group of persons to find that schizophrenia is, if anything, more common in the population in question than in that subsection of it that is presenting to psychiatrists'. This may say more about psychiatric services than about that population. In spite of the article's title we learn nothing about these services in relation to homeless persons.

Priest states that the NAB survey Homeless Single Persons revealed 'approximately 30,000 such persons in Great Britain'. In fact it stated no such thing, instead stressing that many in lodging houses were in no sense 'homeless single persons'; of the latter there were about 13,500. Its definition was not Priest's or the one he attributes to it. It included those in lodging houses, hostels, reception centres, sleeping rough and applying for supplementary benefit when homeless who 'from time to time may sleep rough or use reception centres'. Priest, however, includes all those surveyed, thus taking as his criteria of homelessness what the Government used as locations when trying to measure it. Had Priest's sample been selected not from all residents but, like the Government's, only from those defined by some independent criterion, his findings might have been different.

This raises the whole issue of single homelessness's definition. There is a strong case for rejecting both these definitions for one which treats homelessness more at its face value, and in keeping with recent Government definition is related to the absence or impending loss of accommodation. Priest's definition includes people actually in accommodation. He speaks of residents who have made their home in a lodging house-and neglects many more without homes, like those squatting, staying with family or friends, etc. Recent developments in this field seem to have been overlooked. Only one of his references is post-1970, in spite of the flood of research since then.* The article does not seem to tell us anything new or interesting. Priest has told us of the psychiatric morbidity of a few lodging-house users. But to what purpose? He does not explain the nature-if anyof its relationship or causal connection with their lodging house use. Perhaps as he says 'there is room for much further investigation of this population'. The question is for what reason? It has long been apparent that lodging houses have more than their fair share of those identified as mentally ill. It is hardly surprising that such cheap accommodation would serve as a repository for those seen not to function properly. Their condition surely no longer requires inquiry or description, but change.

Peter Beresford

\section{University of Lancaster, Department of Social Administration, Fylde College, \\ Lancaster $L A I{ }_{4} Y F$}

* See my paper in: 'Report of the Proceedings of a Meeting held on 13th March 1975 to discuss research into the needs of Homeless Single People.'

DeAr SiR,

Many of your readers will know that $I$ am as unhappy as Beresford with the term 'Homeless Single Persons'.

In my last review in the News and Notes section of the foumal, I described this term as cumbersome, potentially misleading, but better than 'tramps', 'vagrants' or 'bums', and probably 'the least unsatisfactory description in common use'.

I believe that most of Beresford's other criticisms of my paper stem from the fact that I was trying to 
present a relatively objective scientific study, rather than making the much needed plea for action to be taken about this population-a plea that I have already endorsed more informally elsewhere (Priest, 1973, 1975). It is in these reviews that I have covered some of the more recent literature (which tends to be of this action-demanding kind rather than being relevant surveys of representative samples).

I should like to try to follow up Beresford's suggestion and carry out a similar study in the general population-comparing the background prevalence of psychiatric symptoms there with rates found in the sample that presents to the psychiatric services. It would be a rather more expensive project, and so far I have been unable to get the money to fund it.

Finally, the NAB publication Homeless Single Persons did give the results on a survey of a representative sample of roughly 30,000 dwellers in common lodging houses, etc. Whether the title refers to this (as I assume) or a sub-section of the population (as Beresford suggests) is probably a matter of opinion. I think that we would both agree that the residents have a roof rather than a home.

Robert G. Priest

Professor of Psychiatry,

University of London

\section{REFERENCRS}

Homeless Single Persons (1966) London: HMSO.

Priest, R. G. (1973) Hospital, Prison or Pad. Review of MIND Report No. 7. British Journal of Psychiatry (News and Notes-January).

- (1975) The health of the homeless. British Journal of Psychiatry (News and Notes-September).

\section{MONOSYMPTOMATIC HYPOCHONDRIASIS, ABNORMAL ILLNESS BEHAVIOUR AND SUICIDE}

DeAr SiR,

I enjoyed Dr Bebbington's well-documented paper on the above topic (Joumal, May 1976, 128, pp 475-8) and I would agree with his statement that 'the treatment of hypochondriasis is difficult'. In fact, so far as psychotic cases are concerned, treatment has conventionally been regarded as well-nigh hopeless.

Dr Bebbington's paper went to press just before the appearance of a paper on monosymptomatic hypochondriasis published by Dr Joyce Riding and myself ( 1 ) in which we describe the striking response in five cases of this disorder to treatment with pimozide. There are, so far as we know, no previous reports of pimozide being used in this way.

Since coming to Canada, I have seen one other case which has responded just as convincingly to the same drug:
A man aged 49 was admitted to the Psychiatric Department, Toronto General Hospital on 25 February 1976, complaining that he smelled unpleasantly because of a leakage of urine. He was convinced that his perineum and legs were soaked in urine, although there was no objective evidence of this or of any unpleasant odour. The symptoms had developed gradually over the previous six months and he was very distressed by them. He could not be convinced that he was mistaken, and he wanted physical treatment, though he accepted admission to the psychiatric unit. $\mathrm{He}$ was not clinically depressed and showed no evidence of thought disorder or of significant personality deterioration. Physical examination was essentially negative.

Three days after admission, pimozide $4 \mathrm{mg}$ in the morning was commenced, and during the ensuing seven days his symptoms gradually abated. He was discharged home two days later and returned to work after a short period of convalescence. He has remained well since, except that when he drinks heavily he becomes convinced for a time that he is again leaking urine, though he does not complain of any smell.

I would therefore temper Dr Bebbington's hithertojustifiable therapeutic pessimism by suggesting that cases of monosymptomatic hypochondriasis of psychotic degree should certainly be given a trial of pimozide.

Department of Psychiatry,

Alistatr Munro

Toronto General Hospital,

Toronto, Ontario $\mathrm{M}_{5} \mathrm{G}_{{ }_{\mathrm{I}} L_{7}}$

REPERENCE

I. Rioing, J. \& Munro, A. (1975) Pimozide in the treatment of monosymptomatic hypochondriacal psychosis. Acta Psychiatrica Scandinavica, 52, 23-30.

\section{NEW LONG-STAY PATIENTS IN A HOSPITAL FOR MENTAL HANDICAP}

\section{Dear Sir,}

Dr Spencer (Journal, May 1976, 128, pp 467-70) concludes his paper '... hospital is the only place with staff and resources to receive and help many mentally handicapped persons whose management is beyond the capability of their families and the local facilities of the Social Service Department . . .

The data presented in his paper only demonstrate that, at present, the existing hospitals receive clients, i.e. that consultants transfer clients into existing hospitals. What is missing is data relating to:

A. The current problems of: 